\title{
Use of tamoxifen, an antioestrogen, in establishing a need for oestrogen in early pregnancy in the bonnet monkey (Macaca radiata)*
}

\author{
N. Ravindranath and N. R. Moudgal \\ Centre for Advanced Research in Reproductive Biology, Department of Biochemistry, \\ Indian Institute of Science, Bangalore 560012, India
}

\begin{abstract}
Summary. Administration of tamoxifen orally $(3 \mathrm{mg} / \mathrm{kg} /$ day $)$ during the post-ovulatory period from Days 16 to 20 or from Days 18 to 30 of female bonnet monkeys mated between Days 9 and 14 of the cycle resulted in inhibition of pregnancy establishment in $90-100 \%$ of monkeys tested. The pregnancy establishment in control female monkeys after exposure to the male during one ovulatory cycle was $66 \%$. The effect of tamoxifen was not due to interference with luteal function because there was no reduction in serum progesterone concentrations after drug treatment. Exogenously administered progesterone could not reverse the inhibitory effect of tamoxifen on pregnancy establishment. The effect of tamoxifen was dose-dependent. We suggest that tamoxifen could be developed as an effective post-ovulatory contraceptive for regulation of female fertility.
\end{abstract}

\section{Introduction}

Progesterone plays an indispensable role in preparing the uterine endometrium for implantation and maintenance of pregnancy in many mammals, including primates. The idea that oestrogen is probably not required for implantation and maintenance of early pregnancy in primates (including the human) stems from the observation that rhesus monkeys ovariectomized within 2-6 days of ovulation or with corpus luteum excision on Day 5 or 6 after ovulation continue pregnancy if treated with progesterone alone (Meyer et al., 1969). Bosu \& Johansson (1975), however, observed that out of 6 ovariectomized monkeys, progesterone treatment maintained pregnancy in only one animal. Several antioestrogens effective in inhibiting implantation in the rat have also been shown to block pregnancy in the rhesus monkey (Morris et al., 1967). Most of these compounds have pronounced oestrogenic activity as well as antioestrogenic activity. Moreover, these compounds were given immediately after mating and so an effect on ovum/blastocyst survival or maturation cannot be discounted.

Implantation occurs between Days 7 and 9 after ovulation in the macaque (Heuser \& Streeter, 1941) and about Days 6-7 in the human (O'Rahilly, 1973). Patterns of circulating oestradiol and total oestrogen during the perimplantation period have been described, for the marmoset (Hearn et al., 1978), rhesus monkey (Anand Kumar et al., 1980), bonnet monkey (Murty et al., 1980), chimpanzee (Hendrickx \& Enders, 1980) and the human (Thomas et al., 1973). Generally the periimplantation concentration of serum oestradiol is higher in the fertile than in the infertile cycle. Although the role of this oestrogen remains unclear, the high concentrations of oestradiol and those of progesterone are used as one of the markers of pregnancy establishment in the non-human primate (Atkinson et al., 1975).

*Reprint requests to Professor N. R. Moudgal. 
We have investigated whether oestrogen is required for the establishment of pregnancy in the bonnet monkey by using a relatively pure antioestrogen, tamoxifen, to deprive the uterus of oestrogenic support at the appropriate time. A preliminary report on the usefulness of tamoxifen in studying oestrogen requirement in early pregnancy in primates has been made (Ravindranath \& Moudgal, 1986).

\section{Materials and Methods}

Animals and husbandry. The experiments described herein required the use of a standardized primate breeding colony whose reproductive endocrinology was well established. The south Indian bonnet monkeys (Macaca radiata) were maintained under standard husbandry conditions as described earlier (Prahalada et al., 1975).

General methodology. All monkeys used in the present study were healthy adult females of recorded proven fertility. The ovulatory nature of the menstrual cycle was established by assaying for oestradiol-17 $\beta$ and progesterone in serum samples obtained from monkeys on Days 7-10 and 14-18 of the cycle respectively. Unless otherwise stated female monkeys which showed high serum oestrogen values between Days 7 and 9 were placed with proven fertile males between Days 9 and 14 of cycle and only those monkeys that showed an increasing trend in progesterone values starting from Day 14 of the cycle were chosen and randomly allotted to the control or experimental group.

Determining the establishment of pregnancy. Based on the observation of Prahalada et al. (1975) that there is a significant increment in the serum progesterone and oestradiol concentrations from Day 25 onwards in bonnet monkeys which have undergone a fertile mating compared to those that have experienced an infertile mating (or that exhibited by unmated cyclic monkeys), the concentrations of these two hormones were used as an early index of pregnancy. Detection of increasing concentrations of chorionic gonadotrophin (CG) from Day 28 onwards (Jagannadha Rao et al., 1984) and rectal palpation, if necessary, around Day 45 provided confirmatory evidence for pregnancy establishment.

Hormones and antioestrogen. Tamoxifen, an antioestrogen (Z)-2(4-(1,2-diphenylbut-1-enyl)phenoxy)- $N, N$ dimethyl ethanamine, was a gift of ICI, U.K., made available by Dr B. J. A. Furr through the WHO, Geneva. Progesterone and medroxyprogesterone acetate used here were products of Steraloids Inc., New Haven, CT, U.S.A. and Upjohn Company, Puurs, Belgium, respectively.

Hormone assays. Blood samples were taken from unanaesthetized monkeys by means of vaccutainer tubes. The sera were separated and stored at $-20^{\circ} \mathrm{C}$ before assay. Radioimmunoassay procedures used for determining oestrogen and progesterone were based on methods standardized and in regular use in this laboratory and described earlier by Prahalada et al. (1975). The serum samples to which an internal standard of tritiated steroid had been added were extracted with diethyl ether. The extracted steroid was measured in duplicate in a liquid-phase system comprising tritiated steroid antigen and antiserum to steroid-BSA conjugate. Dextran-coated charcoal was used to adsorb unbound steroid. The oestradiol assay had an intra-assay coefficient of variation of $12.5 \%$ and a sensitivity of $0.01 \mathrm{ng} / \mathrm{ml}$. The oestradiol antiserum showed a cross-reaction of $10 \%$ with oestrone and $<1 \%$ with oestriol and testosterone.

The progesterone assay had an intra-assay coefficient of variation of $8 \%$ and a sensitivity of $0.01 \mathrm{ng} / \mathrm{ml}$. The progesterone antiserum showed a cross-reaction of $3 \%$ with $17 \alpha$-hydroxyprogesterone and $5 \%$ with $20 \alpha$-dihydroprogesterone.

Radioimmunoassay used for determining chorionic gonadotrophin in fertile cycles of bonnet monkeys was according to the method described by Jagannadha Rao et al. (1984). This consisted of incubating serum samples and hCG standards (range from $100 \mathrm{pg}$ to $100 \mathrm{ng}$ ) and ${ }^{125}$ I-labelled hCG with a rabbit antiserum to ovine LH $\beta$-subunit for $12 \mathrm{~h}$ at room temperature. Bound and free hormone were separated by adding goat anti-rabbit $\gamma$-globulin serum and the radioactivity precipitated was measured in an autogamma spectrometer. The monkey CG in serum samples was expressed as hCG equivalent read from hCG standards used in the assay. The assay had an intra-assay coefficient of variation of $10.8 \%$ and a sensitivity of $5 \mathrm{ng} / \mathrm{ml}$. This assay is specific to CG and does not exhibit cross-reactivity with monkey pituitary extract or serum from castrated monkeys (Jagannadha Rao et al., 1984).

Treatment with tamoxifen. Tamoxifen was administered orally to all animals in the treatment group at 10:00 h; the dose, duration and groups given tamoxifen are described with the relevant experiments. The controls received no treatment. The female monkeys used here weighed $\sim 5 \mathrm{~kg}$ each and all doses administered unless otherwise specified refer to daily doses per monkey computed for $5 \mathrm{~kg}$ body weight.

\section{Results}

Effect of tamoxifen on luteal function and cycle length in cyclic females

Administration of tamoxifen ( $15 \mathrm{mg} /$ day) to a group of 4 cyclic but unmated monkeys from Days 18 to 30 of the cycle resulted in an extension of the luteal phase of the cycle and hence of the 
Table 1. Effect of tamoxifen feeding on cycle length of female bonnet monkeys

\begin{tabular}{cccccc}
\hline Group & $\begin{array}{c}\text { Treatment } \\
\text { duration }\end{array}$ & $\begin{array}{c}\text { Daily dose } \\
\text { (mg) }\end{array}$ & $\begin{array}{c}\text { No. of } \\
\text { females }\end{array}$ & $\begin{array}{c}\text { Length of cycle } \\
\text { (days) }\end{array}$ & $\begin{array}{c}\text { Length of } \\
\text { luteal phase } \\
\text { (days) }\end{array}$ \\
\hline I & Control & - & 6 & $28 \cdot 0 \pm 0.56$ & $17 \cdot 2 \pm 0.5$ \\
II & Days 18-30 & $15 \cdot 0$ & 4 & $58 \cdot 7 \pm 3 \cdot 8^{*}$ & $39 \cdot 0 \pm 5 \cdot 4^{*}$ \\
III & Days 18-30 & 2.5 & 5 & $27.2 \pm 1 \cdot 4$ & $18 \cdot 7 \pm 1 \cdot 4$ \\
IV & Days 16-18 & $15 \cdot 0$ & 2 & $28 \cdot 2$ & $18 \cdot 5$ \\
\hline
\end{tabular}

$\uparrow$ No. of days elapsed between the day of oestradiol surge and end of the cycle.

*Significantly different from controls, $P<0.01$ (Student's $t$ test).

Values are mean \pm s.e.m.
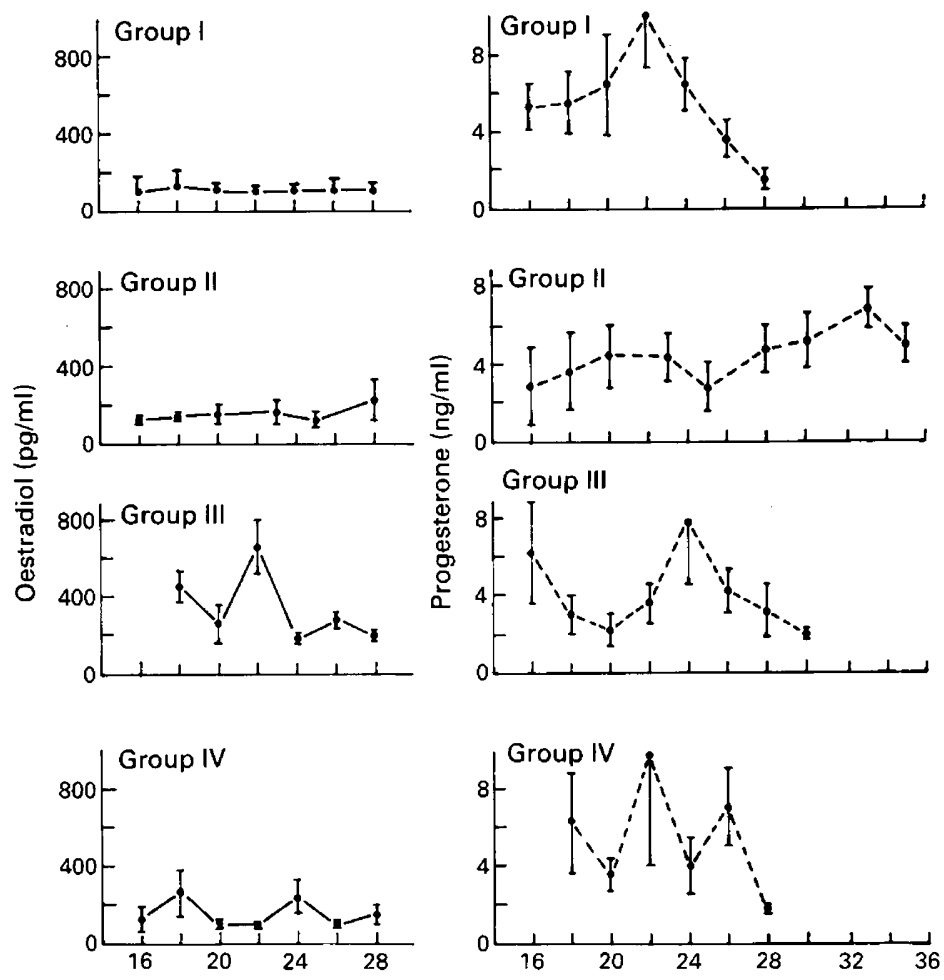

Day of cycle

Fig. 1. Oestradiol $(--)$ and progesterone $(---)$ concentrations (mean \pm s.d.) during the luteal phase of the menstrual cycle in mated female bonnet monkeys fed with tamoxifen. Group I, controls $(\mathrm{N}=6)$; Group II, tamoxifen, $15 \mathrm{mg}$ daily from Days 18 to $30(\mathrm{~N}=4)$; Group III, tamoxifen, $2.5 \mathrm{mg}$ daily from Days 18 to $30(\mathrm{~N}=5)$; Group IV, tamoxifen, $15 \mathrm{mg}$ daily from Days 16 to $18(\mathrm{~N}=2)$.

cycle length (Table 1). Tamoxifen appeared to promote luteal function because progesterone concentrations remained high, even up to the 35 th day after the last menstrual flow, instead of becoming low by Day 26-28, as in the normal cycle (Fig. 1, Group II); tamoxifen had no effect on serum oestrogen concentrations (Fig. 1, Group II). Reducing the dose of tamoxifen to $2.5 \mathrm{mg} /$ day on Days $18-30$ or to $15 \mathrm{mg}$ /day on Days $16-18$ only did not influence cycle length or luteal function (Table 1). Prolongation of luteal function as indicated by high progesterone values beyond Day 28 of the cycle was not seen when tamoxifen dosage was reduced to $2.5 \mathrm{mg} /$ day or the duration of 
exposure to tamoxifen was reduced from 13 days to 5 days (compare Groups III \& IV with I \& II in Fig. 1). The serum oestrogen values after low-dose tamoxifen treatment ( $2.5 \mathrm{mg}$ daily) showed an increase compared to those seen after the $15 \mathrm{mg}$ dose (compare Group III with Groups II \& IV, Fig. 1), but the reasons for this are not apparent at present.

\section{Fertility status of the primate colony}

Since it was planned to study the effect of tamoxifen on the establishment of pregnancy in proven fertile monkeys, it was essential to determine the fertility status of the female monkeys of the colony. Considering the data from mating of monkeys showing an ovulatory cycle only for analysis, the colony showed an overall pregnancy index of $82 \%$ and this was achieved by mating during 3 successive ovulatory cycles. However, $60 \%$ of the ovulatory cycling monkeys that mated became pregnant in the first cycle. The data obtained with the control group of this investigation are consistent with that recorded for the past 5 years for the colony (Table 2). The present series of experiments were carried out during the most fertile period of the year extending from August to March of each year. Data pertaining to conception obtained from only one ovulatory cycle have been included in the current study.

Table 2. Fertility status of female bonnet monkeys held in the colony over a 5-year period

\begin{tabular}{lccccc}
\hline \multirow{2}{*}{$\begin{array}{c}\text { Year } \\
\text { (July-March) }\end{array}$} & $\begin{array}{c}\text { No. } \\
\text { mated }\end{array}$ & \multicolumn{2}{c}{ No. becoming pregnant after exposure: } & Total \% \\
\cline { 3 - 5 } pregnancy
\end{tabular}

Figures in parentheses indicate percentage pregnancies.

\section{Effect of tamoxifen on establishment of pregnancy}

Female monkeys with a proven fertility record were mated individually with proven fertile males between Days 9 and 14 of the cycle. Monkeys that exhibited ovulatory cycles (based on oestrogen and progesterone profiles) were allocated to four groups: monkeys in Group I served as controls and received no treatment, those in Group II received tamoxifen $(15 \mathrm{mg} /$ day $)$ from Days 18 to 30 of the cycle, and those in Groups III and IV received $15 \mathrm{mg}$ tamoxifen/day as in Group II and also s.c. injections of $10 \mathrm{mg}$ medroxyprogesterone acetate (MPA) or progesterone respectively.

Administration of tamoxifen led to prevention of establishment of pregnancy in 9 out of 10 monkeys (Table 3, Group II). In 5 monkeys, the cycle ended on Day 23 and CG could not be detected. Of the remaining 5 monkeys, which were CG-positive on Day 28, 3 exhibited menstruation on Day 29, 1 on Day 56 and one continued pregnancy to term.

Simultaneous administration of MPA or progesterone was not able to override the effect of tamoxifen to any marked extent; only 3 out of 16 monkeys (Table 3, Groups III \& IV) became pregnant. Of 5 monkeys that were treated with MPA (Group III), 4 were CG-positive between Days 28 and 33 and 3 of these showed vaginal bleeding between Days 66 and 77, while one monkey continued pregnancy to term. The 5th monkey, although it was not CG-positive, showed bleeding on the 74th day from the day of last menstrual flow. Considering that MPA has a long half-life and 
Table 3. Demonstration of specificity of tamoxifen (TMX) effect on conferring protection against pregnancy

\begin{tabular}{|c|c|c|c|c|c|}
\hline \multirow[b]{2}{*}{ Group } & \multirow{2}{*}{$\begin{array}{c}\text { Treatment } \\
\text { (duration days) }\end{array}$} & \multirow[b]{2}{*}{ No. mated } & \multicolumn{2}{|c|}{ No. pregnant } & \multirow{2}{*}{$\begin{array}{c}\% \\
\text { protection }\end{array}$} \\
\hline & & & No. expected* & No. recorded & \\
\hline I & Control & 6 & 4 & 4 & 0 \\
\hline II & TMX (18-30) & 10 & 6 & 1 & 84 \\
\hline III & $\begin{array}{l}\text { TMX }(18-30) \\
+ \\
\text { MPA }\end{array}$ & 5 & 3 & 1 & 67 \\
\hline IV & $\begin{array}{l}\text { TMX (18-30) } \\
\quad+ \\
\text { progesterone }\end{array}$ & 11 & 6 & 2 & 72 \\
\hline
\end{tabular}

Except for controls, which did not receive any treatment, all animals received $15 \mathrm{mg}$ tamoxifen daily. Groups III and IV received in addition to TMX, $10 \mathrm{mg}$ daily of medroxyprogesterone acetate (MPA) or progesterone respectively.

${ }^{*}$ Calculated on the basis of colony norms for one exposure only (see Table 2).

no fetal remnants were recovered in the break-through bleeding of any of the 4 monkeys (this is normally to be expected if abortion occurs after Day 50), it was felt that establishment of pregnancy was prevented in these monkeys by tamoxifen treatment, as it was in those of Group II, but menstruation was delayed because of the effect of MPA.

In the progesterone-treated animals (Group IV), 2 out of 11 monkeys continued pregnancy to term. Of the remaining 9, one showed an early end of the cycle (Day 24) and the others showed vaginal bleeding between Days 36 and 48 . Five of these monkeys were CG-positive on Day 28. The remaining 3, which were CG-negative, also showed delay in bleeding and this could be due to continuous administration of progesterone.

\section{Effect of tamoxifen on serum oestrogen and progesterone profiles}

The serum oestrogen concentration of mated monkeys treated with tamoxifen alone (Group II, Fig. 2) was significantly higher than that of the control (Group I, Fig. 2) pregnant monkeys $(P<0 \cdot 01)$. Treatment with progesterone, however, significantly reduced serum oestrogen concentration (Group IV, Fig. 2; $P<0.01$ ). Treatment with MPA also resulted in reduction in serum oestrogen values but this effect was much less than that produced by progesterone (compare Groups III \& IV, Fig. 2).

The serum progesterone concentrations of the tamoxifen-treated mated monkeys were not significantly different from those of the control pregnant monkeys (Groups I \& II, Fig. 2). Progesterone values measured after MPA treatment were not markedly different from those recorded after tamoxifen treatment alone (compare Groups II \& III, Fig. 2), except for Day 28 and beyond. It is not clear whether this reduction in progesterone values on Day 28 and beyond $(P<0.05)$ is a reflection of the antagonistic effect of MPA on the luteotrophic activity of tamoxifen (MPA does not cross-react in the progesterone radioimmunoassay). As expected, serum concentrations of progesterone were markedly increased after treatment with exogenous progesterone (Groups II \& IV, Fig. 2).

\section{Effect of changing tamoxifen dose and schedule of administration on pregnancy establishment}

Proven fertile monkeys were mated between Days 9 and 14 of the cycle and divided into 4 groups. The control group (I) did not receive any treatment, but monkeys in Groups II, III and IV received tamoxifen at $2 \cdot 5,15.0$ and $7.5 \mathrm{mg} /$ day respectively. Monkeys in Groups III and IV 

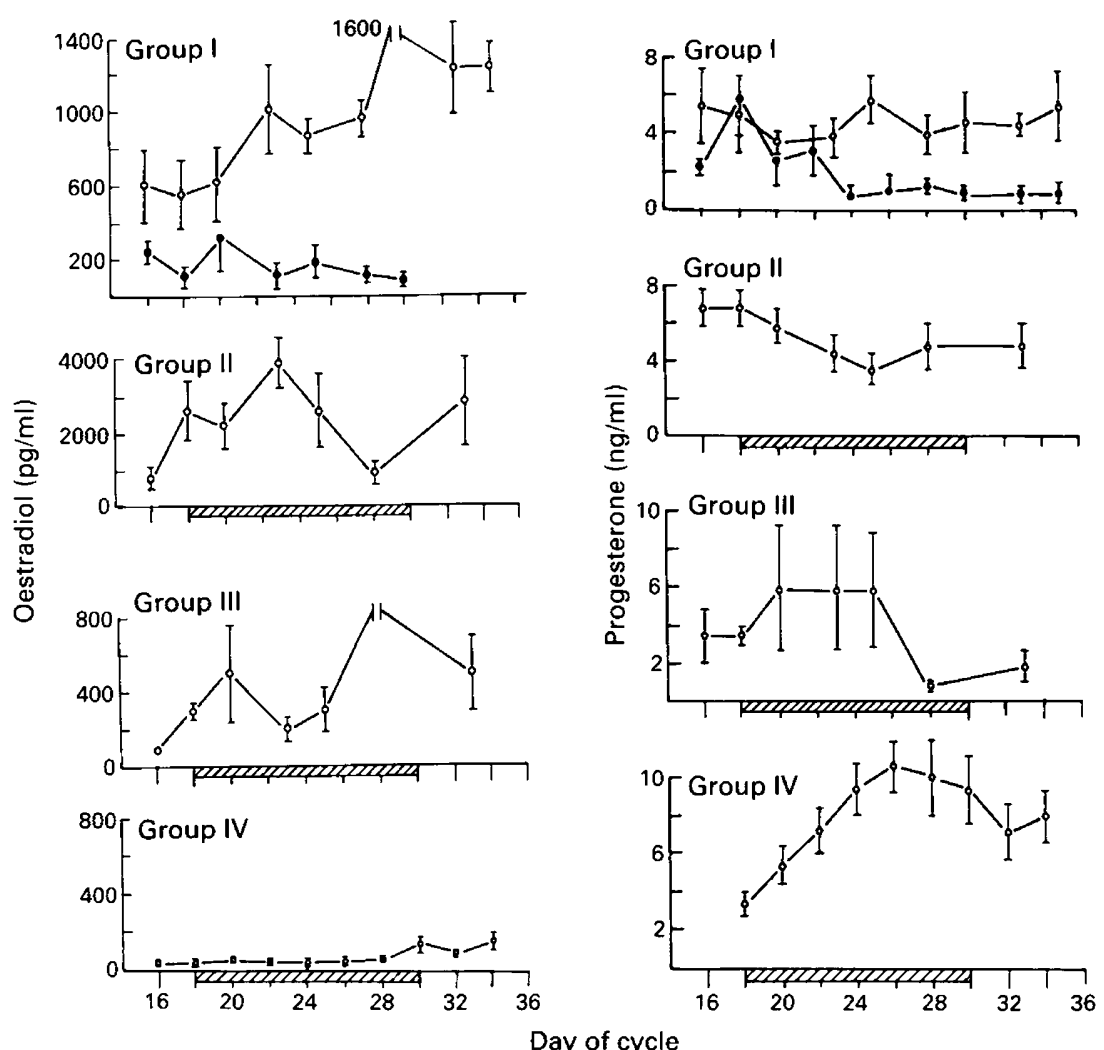

Fig. 2. Oestradiol and progesterone concentrations (mean \pm s.d.) during the luteal phase of the menstrual cycle in mated female bonnet monkeys fed with tamoxifen. Group I, controls: pregnant $(\mathrm{O}-\mathrm{O})(\mathrm{N}=4)$; non-pregnant $(-)(\mathrm{N}=2)$; Group II, tamoxifen, $15 \mathrm{mg}$ daily from Days 18 to $30(\mathrm{~N}=9)$; Group III, tamoxifen, $15 \mathrm{mg}$ daily from Days 18 to 30 and MPA, $10 \mathrm{mg}$ daily from Days 18 to $30(\mathrm{~N}=4)$; Group IV, tamoxifen, $15 \mathrm{mg}$ daily from Days 18 to 30 and progesterone, $10 \mathrm{mg}$ daily from Days 18 to $30(\mathrm{~N}=9)$. In Groups II, III and IV, the steroid profiles of only those animals in which pregnancy was blocked are shown.

received tamoxifen from Days 16 to 20 of the cycle, but those in Group II were treated from Days 18 to 30 of the cycle. The control group of females showed a normal conception rate of $60 \%$ after one ovulatory cycle exposure to males, but conception in the other groups was reduced (Table 4). The hormone concentrations in these females are shown in Fig. 3.

The ability of tamoxifen to promote progesterone production when given at the daily dose of $15 \mathrm{mg}$ for 13 days (Fig. 2) was abolished by reducing the daily dose to $2.5 \mathrm{mg}$ (Fig. 3, Group II and/or shortening the duration of treatment to 5 days (Fig. 3, Groups III \& IV). The progesterone profile beyond Day 24 of the cycle after $2.5 \mathrm{mg}$ ( 13 days) or $7.5 \mathrm{mg}$ ( 5 days) tamoxifen was significantly different from that observed when $15 \mathrm{mg}$ tamoxifen were given for 13 days $(P<0.05)$. The effect of tamoxifen on oestrogen production was also substantially diminished by reducing the dose and/or duration of treatment (compare Fig. 3, Groups III \& IV with Fig. 2, Group II; $P<0.05$ ).

\section{Effect of tamoxifen on post-treatment cycles}

With the high dose of tamoxifen ( $15 \mathrm{mg}$ for 13 days), the immediate post-treatment cycle was usually extended from a mean ( \pm s.d.) of $28 \cdot 0 \pm 4 \cdot 3$ to $46 \cdot 4 \pm 20 \cdot 2$ days. The following cycle 
Table 4. Effect of altered tamoxifen regimen and schedule on pregnancy establishment in bonnet monkeys

\begin{tabular}{clccccc}
\hline & & & \multicolumn{2}{c}{ No. pregnant } & \\
\cline { 5 - 6 } Group & Treatment* & $\begin{array}{c}\text { Duration } \\
\text { (days) }\end{array}$ & No. mated & No. expected $\ddagger$ & No. recorded & $\begin{array}{c}\% \\
\text { protection }\end{array}$ \\
\hline I & Control & & 10 & 6 & 6 & 0 \\
II & TMX (2.5 mg) & $18-30$ & 10 & 6 & 2 & 66 \\
III & TMX (15.0 mg) & $16-20$ & 5 & 3 & 0 & 100 \\
IV & TMX (7.5 mg) & $16-20$ & 10 & 6 & 1 & 84 \\
\hline
\end{tabular}

*Number in parentheses indicates daily dose per monkey.

$\dagger$ Refers to days of cycle for which treatment was given.

$\$$ Calculated on the basis of colony norms for one exposure only (see Table 2).
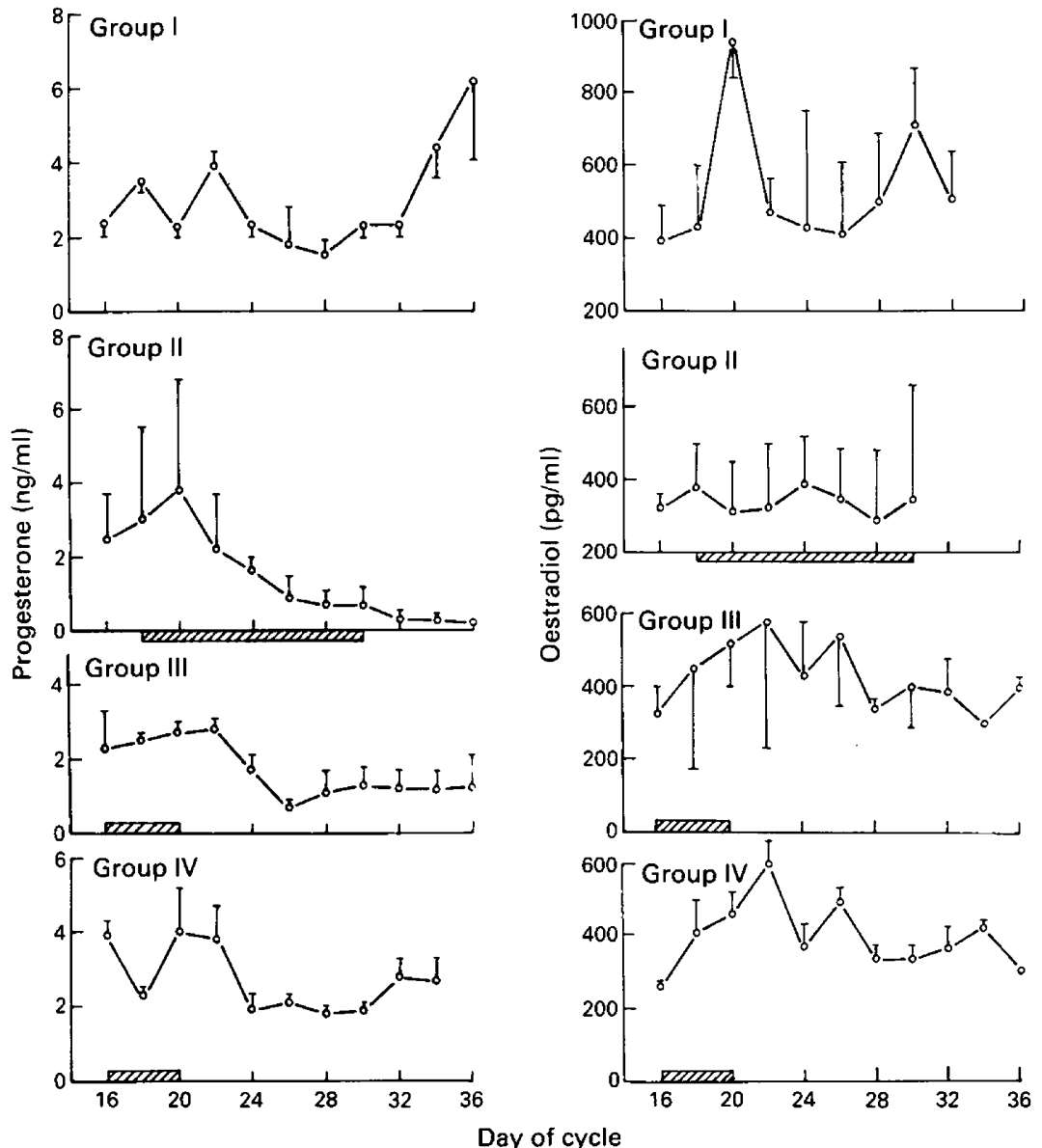

Fig. 3. Progesterone and oestradiol concentrations (mean \pm s.d.) during the luteal phase of the menstrual cycle in mated female bonnet monkeys fed with tamoxifen at different doses and schedules. Group I, controls $(\mathrm{N}=10$ ); Group II, tamoxifen, $2.5 \mathrm{mg}$ daily from Days 18 to 30 $(\mathrm{N}=10)$; Group III, tamoxifen, $7.5 \mathrm{mg}$ daily from Days 16 to $20(\mathrm{~N}=10)$; Group IV, tamoxifen, $15 \mathrm{mg}$ daily from Days 16 to $20(\mathrm{~N}=5)$. In Groups II, III and IV, the steroid profiles of only those animals in which pregnancy was blocked are shown. 
(treatment plus 2 cycles) was normal (with regard to length and hormonal profiles) and mating during the $3 \mathrm{rd}$ or 4 th post-treatment cycle resulted in most of the females becoming pregnant. Reducing the dosage of tamoxifen exposure to 5 days only ( $15 \mathrm{mg}$ daily from Days 16 to 20 only) or lowering the daily dosage $(2.5 \mathrm{mg}$ daily for 13 days) had no effect on the cycle length of hormonal profile of the post-treatment cycle and all the monkeys became pregnant after mating in subsequent cycles.

\section{Discussion}

The functional significance of luteal-phase oestrogen in the primate, particularly that of the pregnant cycle, remains unclear. Besides its own receptor concentration in the uterus, oestrogen is known to regulate that of progesterone (Kreitmann et al., 1979). It is, however, unclear to what extent progesterone receptor turnover is dependent upon oestrogen and whether this dependency is influenced by preovulatory and luteal phase concentration. Sankaran et al. (1984) administered Zuclomiphene, an oestrogen antagonist (also known to have agonistic activity in the primate at some doses), to female rhesus monkeys from Days 5 to 11 of the cycle, followed by mating between Days 9 and 15 of the cycle. The dose used $(2 \mathrm{mg} / \mathrm{kg}$ body weight) apparently did not block ovulation but prevented conception in 4 out of 5 monkeys. In a few other instances in which antioestrogens have been tested in monkeys, the compounds have been given within $24 \mathrm{~h}$ of mating (Morris et al., 1967). As far as we are aware, except for one study with marmosets, tamoxifen has not been tested for its antifertility effects in primates. In the marmoset study, 4 out of 6 females treated with $0.2 \mathrm{mg}$ tamoxifen $/ \mathrm{kg} /$ day for 6 months remained non-pregnant for the duration of treatment (Furr et al., 1979).

Ovulation occurs in the bonnet monkey by Day 11-12 of the cycle (N. Ravindranath \& N. R. Moudgal, unpublished observation). In a fertile cycle, fertilization occurs within $24 \mathrm{~h}$ of ovulation and implantation by Day 19-21 (Enders \& Hendrickx, 1980). By starting tamoxifen treatment 3-5 days after fertilization, we have minimized any oestrogenic effect it could be having on tubal transport. The results of the current study show that tamoxifen is effective in interfering with the establishment of pregnancy even when its administration is started as late as Day 16 or 18 of the cycle. The percentage protection against pregnancy conferred by tamoxifen ranged from $66 \%(2.5 \mathrm{mg} /$ day for 13 days) to $100 \%$ ( $15 \mathrm{mg} /$ day for 5 days). The study shows that the efficacy of the drug (Table 4) is dependent not only on the dose and duration of administration but also on the time of start of treatment (from Day 16 instead of Day 18). Statistical analysis of data pooled from Tables 3 and 4 shows that tamoxifen is efficient at preventing conception (Table 5). Exogenous progesterone treatment did not markedly vary the effect.

In the pregnant rhesus monkey the ratio of endometrial nuclear oestrone/oestradiol receptors increases from 0.50 on Day 5 to 0.80 on Day 18 and to 2.45 on Day 24 of a fertile cycle (KreitmannGimbal et al., 1981). Assuming that the bonnet monkey also exhibits a uterine oestrogen receptor pattern like that of the rhesus monkey, it was considered desirable to start tamoxifen treatment from Day 16 of the cycle, well before the onset of the increase in nuclear oestrogen receptors. The relatively long half-life of the drug ( 7.5 days; Fromson et al., 1973) also prompted us to reduce the duration of exposure to 5 days only. Neither of these manipulations affected the overall efficacy of the drug.

Tamoxifen could be promoting luteal function in the bonnet monkey by increasing basal concentrations of LH or antagonizing any natural luteolytic activity oestrogen may exhibit (Karsch et al., 1973). The luteal tissue is known to have oestrogen receptors although their role in regulating progesterone production remains obscure. Tamoxifen-treated monkeys showed an increase or no change in serum oestrogen concentrations. This increase could be due to tamoxifen affecting catabolism of oestrogen by occupying its receptor sites in the liver. Progesterone treatment brought about a marked suppression in serum oestrogen concentrations, but the mechanism by which this is achieved is not known. 
Table 5. Statistical analysis of data pooled from Tables 3 and 4 for significance

\begin{tabular}{clccc}
\hline Group & Treatment & No. mated & $\begin{array}{c}\text { Pregnancies } \\
\text { recorded }\end{array}$ & Contingency test* \\
\hline I & Control & 16 & 10 & \\
II & Tamoxifen & 35 & 4 & I:II, $P<0.01$ \\
III & Tamoxifen + & 16 & 3 & I:III, $P<0.05$ \\
& progestagen & & & II:III, not-significant
\end{tabular}

For Groups II and III, irrespective of dosage and duration of treatment, data of all monkeys given tamoxifen alone or tamoxifen + progestagen respectively have been considered.

*According to the method of Mainland \& Murray (1952).

The results of the present study are at variance with the conclusion of Meyer et al. (1969) that progesterone alone can maintain early pregnancy in the primate. Although the reason for this is not evident at present, it is possible that the experimental animal used has influenced the overall results obtained. Ovariectomized monkeys, according to Bosu \& Johansson (1975), still have basal values of oestrogen (perhaps adrenal in origin) and these may be adequate to maintain the receptor load once the preovulatory oestrogen induces receptors in the endometrium.

The mechanism by which tamoxifen is expressing its antifertility activity in primates is currently unknown. By delaying the start of tamoxifen administration, any oestrogenic effect it may have on tubal transport is circumvented and the present study also shows that it has no inhibitory effect on ovarian steroid production. The possibility of the drug influencing the uterine microenvironment making it hostile for implantation or for the blastocyst to survive has to be considered.

The present study (1) shows that there is a definitive need for oestrogen for pregnancy establishment in the primate and (2) demonstrates the efficacy of an antioestrogen such as tamoxifen to serve as a post-ovulatory contraceptive. Although no direct data are available on changing patterns of oestrogen receptors during the peri-implantation period of women, if women in early pregnancy exhibit a pattern very similar to that of the rhesus monkey during Days 15-24 of the mated cycle, administration of tamoxifen during the early secretory phase in women (Days 16-20) is likely to antagonize the action of oestradiol during this critical phase. The attractiveness of tamoxifen as a contraceptive lies in the fact that it is a specific antagonist of oestrogen and does not exhibit any antiglucocorticoid activity. Furthermore, tamoxifen appears to be a safe drug and a considerable body of information is available on its usage in women (Furr et al., 1979).

Aided by grants from the Special Programme for Research in Human Reproduction, WHO, Geneva (Project Nos 83016 and 85012) and the Indian Council of Medical Research, New Delhi, India. We thank Professor M. R. N. Prasad for a critical review of the data and manuscript.

\section{References}

Anand Kumar, T.C., David, G.F.X., Sharma, D.N., Puri, C.P., Puri, V., Dubey, A.K., Seghal, A., Shankarnarayanan, A. \& Pruthi, J.S. (1980) Reproductive profile of the rhesus monkey with reference to the testing of contraceptives. In Nonhuman Primate Models for Study of Human Reproduction, pp. 37-49. Ed. T. C. Anand Kumar. S. Karger, Basel.

Atkinson, L.E., Hotchkiss, J., Fritz, G.R., Surve, A.H., Neill, J.D. \& Knobil, E. (1975) Circulating levels of steroids and chorionic gonadotropin during pregnancy in the rhesus monkey, with special attention to the rescue of the corpus luteum in early pregnancy. Biol. Reprod. 12, 335-345.
Bosu, W.T.K. \& Johansson, E.D.B. (1975) Implantation and maintenance of pregnancy in mated rhesus monkeys following bilateral oophorectomy or luteectomy with and without progesterone replacement. Acta endocr., Copenh. 79, 598-609.

Enders, A.C. \& Hendrickx, A.G. (1980) Implantation in nonhuman primates. I. A comparison of morphological events. In Nonhuman Primate Models for Study of Human Reproduction, pp. 99-108. Ed. T. C. Anand Kumar. S. Karger, Basel.

Fromson, J.M., Pearson, S. \& Bramah, S. (1973) The metabolism of tamoxifen (ICI 46474). Part I: In laboratory animals. Xenobiotica 3, 693-709. 
Furr, B.J.A., Patterson, J.S., Richardson, D.N., Slater, S.R. \& Wakeling, A.E. (1979) Tamoxifen. In Pharmacological and Biochemical Properties of Drug Substances, Vol. 2, pp. 355-399. Ed. M. E. Goldberg. American Pharmaceutical Association, Washington, D.C.

Hearn, J.P., Abbot, D.M., Chambers, P.C., Hodges, J.K. \& Lunn, S.F. (1978) Use of the common marmosets, Callithrix jacchus, in reproductive research. Prim. Med. 10, 40-49.

Hendrickx, A.G. \& Enders, A.C. (1980) Implantation in nonhuman primates: II. Endocrinology. In Nonhuman Primate Models for Study of Human Reproduction, pp. 109-115. Ed. T. C. Anand Kumar. S. Karger, Basel.

Heuser, C.H. \& Streeter, G.L. (1941) Development of the macaque embryo. Contr. Embryol. Carneg. Instn 29, 17-228.

Jagannadha Rao, A., Kotagi, S.G. \& Moudgal, N.R. (1984) Serum concentrations of chorionic gonadotrophin, oestradiol-17 $\beta$ and progesterone during early pregnancy in the south Indian bonnet monkey (Macaca radiata). J. Reprod. Fert. 70, 449-455.

Karsch, F.J., Krey, L.C., Weick, R.F., Dierschke, D.J. \& Knobil, E. (1973) Functional luteolysis in the rhesus monkey: the role of estrogen. Endocrinology 92, $1148-1152$.

Kreitmann, B., Bugat, R. \& Bayard, F. (1979) Estrogen and progestin regulation of the progesterone receptor concentration in human endometrium. $J$. clin. Endocr. Metab. 49, 926-929.

Kreitmann-Gimbal, B., Bayard, F. \& Hodgen, G.D. (1981) Changing ratios of nuclear estrone to estradiol binding in endometrium at implantation: regulation by chorionic gonadotropin and progesterone during rescue of primate corpus luteum. J. clin. Endocr. Metab. 52, 133-137.

Mainland, D. \& Murray, I.M. (1952) Tables for use in fourfold contingency tests. Science, N.Y. 116, 591-594.
Meyer, R.K., Wolf, R.C. \& Arslan, M. (1969) Implantation and maintenance of pregnancy in progesterone treated ovariectomised monkeys (Macaca mulatta). In Recent Advances in Primatology, Vol. 2, pp. 30-35. Ed. A. Hofer, S. Karger, Basel.

Morris, J.M., Van Wagenen, G., McCann, T. \& Jacob, D. (1967) Compounds interfering with ovum implantation and development (ii) synthetic estrogens and antiestrogens. Fert. Steril. 18, 18-34.

Murty, G.S.R.C., Ramasharma, K., Mukku, V.R., Srinath, B.R. \& Moudgal, N.R. (1980) Reproductive endocrinology of bonnet monkeys. In Nonhuman Primate Models for Study of Human Reproduction, pp. 50-54. Ed. T. C. Anand Kumar. S. Karger, Basel.

O'Rahilly, R. (1973) Developmental stages in human embryos. Part A: Embryos of the first three weeks (stages 1-9). Carneg. Instn, Wash. Publ. 631.

Prahalada, S., Mukku, V., Jagannadha Rao, A. \& Moudgal, N.R. (1975) Termination of pregnancy in macaques (Macaca radiata) using monkey antiserum to ovine luteinizing hormone. Contraception 12, $137-147$.

Ravindranath, N. \& Moudgal, N.R. (1986) Antifertility effect of tamoxifen as tested in the female bonnet monkey (Macaca radiata). J. Biosci. 10, 167-170.

Sankaran, M.S., Prahalada, S. \& Hendrickx, A.G. (1984) Effects of Zuclomiphene citrate on the nonfertile and fertile menstrual cycles in the rhesus monkey (Macaca mulatta). An experimental approach to the understanding of the role of periovulatory estrogens in implantation in primates. Am. J. Primatol. 7, 309, Abstr.

Thomas, K., De Hertogh, R., Pizarro, M., Van Exter, C. \& Ferin, J. (1973) Plasma LH-HCG, 17ß-estradiol, estrone and progesterone monitoring around ovulation and subsequent nidation. Int. J. Fertil. 18, 65-73.

Received 10 December 1986 